\title{
IMP.ORTANCLA DE LOS FLUJOS FINANCIEROS EN EL CRECIMIENTO DE PAÍSES EMERGENTES
}

\author{
Dra. Beatriz Hertera Garcia*
}

\begin{abstract}
RESUMEN
La globalización hace referencia a la integración de los diversos mercados financieros domésticos en un único mercado financiero mundial, lo que permite a los agentes de cualquier pais que busquen fondos y no limitarse a localizarlos en su propio mercado interno.

Laglobalización como proceso se distingue de los procesos anteriores de internacionalización de la economía mundial. Los principales rasgos de la globalización son la gradual generalización del libre comercio, la creciente presencia en el escenario internacional de empresas transnacionales que funcionan como sistemas mundiales de producción integrada, la expansión y considerable movilidad de los capitales unida a la persistencia de las restricciones al movimiento migratorio de la mano de obra (1), y al acceso masivo a la información en tiempo real (propiciada por el desarrollo de tecnologías de información y comunicaciones) (2). Asimismo, se advierte una notable tendencia a la homogeneización de los modelos de desarrollo.

Entre los hechos destacados de la globalización, la volatilidad ha primado en los mercados financieros internacionales, sus características contemporáneas han tendido a acentuarla. Su principal reflejo ha sido las frecuentes crisis financieras. Los mercados dependen de las expectativas y éstas fluctúan entre el optimismo y el pesimismo de acuerdo con el nivel de riesgo (3).
\end{abstract}

A diferencia de los decenios anteriores, las fuentes de financiamiento fueron procíclicas; así, la inversión extranjera directa y la colocación de bonos fueron las principales fuentes de financiamiento en los años noventa. La IED mostró un considerable crecimiento y aportó en promedio; $3 / 4$ partes de los flujos netos de capitales hacia los países subdesarrollados. En marcado contraste, las emisiones de bonos fueron fluctuantes y sus condiciones de financiamiento muy sensibles a los cambios de los mercados internacionales. Asimismo, los flujos netos de la banca comercial mostraron tendencias similares, en tanto que los flujos de cartera accionaria y la colocación de títulos de depósitos en los mercados internacionales (ADRs y GDRs) mostraron el mayor grado de inestabilidad.

- Docente Investigadora Principal de la Facultad de Ciencias Contables y primera mujer Vicerrectora Administrativa de la UNMSM 
Sin embargo, la globalización presenta oportunidades y conlleva riesgos importantes (4), tales como:

- Acceso generalizado a la información, al conocimiento, la tecnologia y las innovaciones. Este nuevo acceso hace posible, entre otros, que los paises subdesarrollados salten etapas en la carrera hacia el progreso. E.g., casos de las telecomunicaciones, la educación y el sistema financiero.

- Mayor acceso a flujos globales de capital de riesgo y al crédito. Los mayores flujos financieros resultantes contribuyen a tasas de crecimiento mas altas, pero dado sus volúmenes y la rapidez que pueden revertir su dirección resultan altamente desestabilizadores y ocasionan graves crisis. E.g., crisis asiática.

- Mayor acceso a bienes y servicios globales de calidad. Aspecto que fortalece la asociación entre crecimiento exportador y crecimiento económico., además de las nuevas formas de especialización y flujos de inversión, como los vinculados con la fragmentación de la producción (clusters) que antes se llevaba a cabo en forma integrada.

- Mayor acceso directo a las oportunidades globales de negocios, cultura y recreación: las politicas de inmigración puestas en práctica por los paises desarrollados han hecho que en la presente ola de globalización la migración haya estado más restringida que en el pasado.

- Posibilidades de protección de bienes públicos de carácter global.

Los factores anotados en su conjunto, presentan oportunidades para el desarrollo económico, sin embargo, los paises subdesarrollados continúan atrapados en una trampa de pobreza y en una mayor desigualdad entre naciones ricas y pobres.

No obstante, la posibilidad de que el proceso de globalización en curso (5) resulte en una mayor varianza de resultados se ve acentuada por los riesgos de crisis vinculados, especialmente, con la alta volatilidad de los flujos financieros.

En suma, cálculos preliminares demuestran que la eliminación de restricciones comerciales $y$ subsidios a la agricultura, servicios y algunos sectores de manufactura, haria mucho más por el desarrollo que doblar los niveles de ayuda externa; e indican que la adopción de políticas de inmigración más abiertas podria tener un efecto aún mayor en materia de reducción de pobreza (6).

La globalización de los mercados facilita que los recursos se enfoquen a la relación óptima entre riesgo y rendimiento, propiciando mayor eficiencia en los flujos de capital y hace que los recursos fluyan cada vez con mayor facilidad hacia las economias (7) que, por su grado de desarrollo y su potencial, ofrezcan las mejores perspectivas de crecimiento y estabilidad. 


\section{Cuadro 1}

AMÉRICA LATINA: VALOR DE LAS OPERACIONES DE PRIVATIZACIÓN 1990-1997 (En millones de dólares)

\begin{tabular}{|l|l|l|l|l|l|l|l|l|r|}
\hline \multicolumn{1}{|c|}{ PAÍ́ } & $\mathbf{1 9 9 0}$ & $\mathbf{1 9 9 1}$ & $\mathbf{1 9 9 2}$ & $\mathbf{1 9 9 3}$ & $\mathbf{1 9 9 4}$ & $\mathbf{1 9 9 5}$ & $\mathbf{1 9 9 6}$ & $\mathbf{1 9 9 7}$ & TOTAL \\
\hline Argentina (a) & 2,139 & 1,896 & 5,312 & $\mathbf{4 , 5 8 9}$ & 1,441 & 1,430 & 1,033 & 969 & 18,719 \\
\hline Bolivia & & & 7 & 14 & & 848 & 874 & & 1,743 \\
\hline Brasil & & 1,564 & 2,451 & 2,621 & 1,972 & 910 & 3,752 & 17,400 & 30,670 \\
\hline Colombia & 117 & 105 & 27 & 4 & 681 & 138 & 1,476 & 3,180 & 5,728 \\
\hline Chile & 29 & 117 & 21 & & 203 & 3 & 579 & 12 & 964 \\
\hline México & 3,580 & 10,716 & 6,799 & 2,507 & 771 & & & 84 & 24,457 \\
\hline Perú (a) & & 3 & 208 & 317 & 2,578 & 946 & 2,460 & 421 & 6,933 \\
\hline Venezuela & 10 & 2,276 & 30 & 32 & 15 & 21 & 2,090 & 1,505 & 5,979 \\
\hline Otros & 1 & 25 & 31 & 95 & 868 & 75 & 68 & 837 & 2,000 \\
\hline TOTAL & 5,876 & 16,702 & 14,886 & 10,179 & 8,529 & 4,281 & 12,332 & 24,408 & 97,193 \\
\hline
\end{tabular}

Fuente. Cepal, sobre la base de cifras oficiales, Santiago de Chile, 1998. (a) Incluye concesiones.

\section{TENDENCIAS RECIENTES EN LOS MERCADOS FINANCIEROS}

En los años recientes, los mercados financieros han sufrido algunas transformaciones más rápidas y extensivas que cualquier mercado. Éstos incluyen las crisis asiática, rusa y la quiebra de la empresa Lon Term Capital Management, un fondo de cobertura de riesgo con un alto grado de apalancamiento y enormes posiciones de mercado. También se han presenciado variaciones espectaculares de los precios de las acciones en todo el mundo, y particularmente de las acciones pertenecientes a las empresas que operan en los sectores de telecomunicaciones e internet, llamadas "acciones tecnológicas", cuyos precios experimentaron grandes alzas a finales de 1999 y principios de 2000, han sufrido reducciones sustanciales, posteriormente, en el valor de mercado de su capital.
También, los mercados financieros globales han experimentado grandes cambios estructurales en años recientes. Es el caso de la zona del euro, cuyos cambios se han dado en una velocidad y amplitud impresionantes, después de la introducción de la nueva divisa.

El cambio reciente más importante en los mercados financieros globales ha sido su acelerada integración y globalización, fomentada por la liberalización de los mercados y el rápido progreso tecnológico, asi como por los notables avances en las telecomunicaciones. Todo ello ha creado nuevas oportunidades de inversión y financiamiento para los agentes en todo el mundo. La mayor facilidad de acceso para individuos y empresas a los mercados financieros globales llevará a una asignación más eficiente del capital y promoverá el crecimiento económico.

Recientemente, además de la integración y globalización en curso, los mercados financieros mundiales 
también han experimentado un aumento de las operaciones bursátiles. En parte, debido a una oleada de fusiones y adquisiciones apalancadas (leveraged buyouts, LBO), ocurrida últimamente en los mercados y en particular en la zona del euro (8). Un aspecto de este proceso de bursatilización ha sido el incremento de la emisión de bonos corporativos (empresariales).

\section{Mercados de Instrumentos Derivados}

Otros acontecimientos interesantes en los mercados financieros mundiales incluyen la continua expansión de los mercados de instrumentos derivados. La ampliación de dichos mercados se debió principalmente a que los rápidos avances conseguidos en tecnologia, ingeniería financiera y administración de riesgos han contribuido a mejorar tanto la oferta como la demanda de productos derivados más complejos y sofisticados.

El incremento en el uso de los instrumentos derivados para enfrentar la exposición al riesgo en los mercados financieros también ha contribuido al aumento de las cantidades técnicas de los contratos de derivados vigentes en los últimos años. Esto ha ocurrido, en particular, en los mercados extra bursátiles de derivados que utilizan tasas de interés y acciones ordinarias como títulos subyacentes. Aunque el apalancamiento que se asume en los instrumentos derivados presenta un riesgo para los inversionistas individuales, los derivados también ofrecen una alternativa para la asignación más eficiente de los riesgos en la economía (9). Esto último resulta beneficioso para el funcionamiento de los mercados financieros, lo que influye positivamente sobre el crecimiento económico.

Por otro lado, el advenimiento del euro ha cimentado las bases para un mercado de valores que abarque a toda Europa (10). El mercado del dinero en la zona del euro experimentó un amplio proceso de integración y de estandarización después de la introducción de un marco único de la política monetaria. Los mercados de depósitos no garantizados y de derivados se integraron completamente a principios de 1999.

\section{LA GLOBALIzACIÓN DE LOS MERCADOS}

La globalización financiera se inicia y cobra gran relevancia (11), en la medida en que las economias de los paises se interrelacionan cada vez más a través del intercambio de servicios. Los avances en tecnologias en sistemas y comunicación han mostrado ser elementos fundamentales para la integración. En este contexto, la internacionalización de la intermediación financiera ha sido parte integral del proceso y en la práctica ha abarcado tanto el sector bancario como los mercados de capitales y deuda (mercado de bonos).

Se entiende por mercado global la interacción de los principales centros financieros internacionales, que hace posible la negociación continua (durante las 24 horas) y en la cual intervienen intermediarios, instrumentos y emisores globales, utilizando redes de información internacionales, tales como Reuters, Bloomberg, etc. En el mercado global se pueden diferenciar los mercados principales: mercados de dinero y de capitales; 
los mercados alternos o auxiliares, como son los mercados de divisas y de metales preciosos, y los derivados, que involucran a los mercados de opciones, futuros, swaps y otros instrumentos.

En el mercado global se realiza virtualmente todo tipo de operaciones, tanto a nivel nacional como internacional y se caracteriza por su elevado grado de liquidez y por la ausencia de trabas o candados para el libre flujo de capitales. Como resultado de la creciente globalización en los mercados financieros, se incrementó la eficiencia al reducirse los costos de intermediación, al tiempo que se observa un incremento en las alternativas de protección contra riesgos relacionados con el tipo de cambio, la tasa de interés y la volatilidad en el precio de los valores.

En el campo de las regulaciones en los mercados financieros, la globalización ha facilitado, tanto a las emisoras como a los intermediarios, extender sus operaciones a mercados fuera de las fronteras nacionales, ampliando sus redes de distribución y comercialización a otros países. La globalización ha provocado la necesidad de estandarizar la información financiera de emisoras a través de la definición de principios y prácticas contables aceptadas, así como la importancia de establecer normas y procedimientos para la custodia, liquidación y administración de valores. La estrecha cooperación entre autoridades y organismos autorregulados juega también un rol determinante en un mercado global sólido y confiable.

\section{CONCLUSIONES}

La definición generalmente aceptada de mercado global es la interacción de los principales centros financieros internacionales, que hace posible la negociación continua y en la cual intervienen intermediarios, instrumentos $y$ emisoras globales, utilizando redes de información internacionales.

Por otro lado, en términos generales, se reconoce que la actividad financiera que va más allá de las fronteras nacionales permite a las empresas captar recursos a costos menores de los que obtendrian en sus mercados locales. Asimismo, los inversionistas, principalmente institucionales, han podido diversificar su portafolio $y$ obtener mayores ventajas derivadas de rendimientos y oportunidades de cobertura (12), en relación con las que tendrian al limitarse al ámbito de inversión en sus países de origen. La incorporación a sus carteras de inversión de valores extranjeros negociados en los mercados auxiliares o derivados, ha acelerado el proceso de internacionalización de los activos financieros.

La globalización de los mercados facilita que los recursos se enfoquen a la relación óptima entre riesgo y rendimiento, propiciando mayor eficiencia en los flujos de capital y hace que los recursos fluyan cada vez con mayor facilidad hacia las economias (12) que por su grado de desarrollo y su potencial, ofrezcan las mejores perspectivas de crecimiento y estabilidad. 


\section{NOTAS Y REFERENCIAS BIBLIOGRÁFICAS}

(1) Cepal, Globalización y desarrollo, Santiago de Chile, 2000, p. 4. La Cepal caracteriza tres fases de globalización correspondientes a los periodos: 1870-1913; 1945-1973, y desde 1974.

(2) Cepal, op. cit, p. 7.

(3) Climent Diranzo, F.J. y V. Meneu Ferrer, La Globalización de los mercados financieros internacionales, Universidad de Valencia, España, 2000, pp.3-4.

(4) Perry, Guillermo, "A modo de conclusión", Conferencia sobre globalización, Banco Mundial, Chile, marzo 2002.

(5) «Las dos últimas décadas han sido testigos de un crecimiento espectacular de los mercados financieros en el mundo, incluyendo los mercados cambiarios, los euromercados y los mercados de bonos internacionales. E.g., el volumen diario de los mercados cambiarios es superior al millón de millones de dólares, lo que es equivalente a casi 10 veces el volumen diario de transacciones comerciales tanto de bienes como de servicios a nivel mundial". (Botello, M.H., Finanzas estratégicas, Invertia, Centro Bursátil de Monterrey, México, 21/09/2000, p. 47).

(6) Soros, George, La crisis del capitalismo global. La Sociedad Abierta en peligro Madrid, 1998, p. 14.

(7) González, S. y J. Mascareñas. La globalización de los mercados financieros, Universidad Complutense de Madrid, España, 1999, p. 16.
(8) Mascareñas Pérez-Iñigo, J., Fusiones y adquisiciones de empresas, Me Graw Hill de Management, Madrid, 2000, pp. 161-169. El lanzamiento del euro el primero de enero de 1999 fue un evento histórico, según el autor.

(9) Duisenberg, W. F., Acontecimientos y tendencias recientes en los mercados financieros mundiales, Banco de México, México, 2000, p. 30.

(10) El resultado de la introducción de una sola moneda en un conjunto de mercados más eficientes y funcionales, su existencia y operación benefician a residentes europeos y a los participantes de mercado fuera de dicha zona. Además, el mercado europeo todavía tiene un gran potencial de expansión. Al respecto, destaca que el uso del funcionamiento por medio de la emisión de valores por el sector corporativo, comparado con el funcionamiento bancario, alcanza apenas la mitad de su análogo en los Estados Unidos (Mascareñas, op. cit. pp. 14-18).

(11) "Las dos últimas décadas han sido testigos de un crecimiento espectacular de los mercados financieros en el mundo, incluyendo los mercados cambiarios, los euromercados y los mercados de bonos internacionales. E.g., el volumen diario de los mercados cambiarios, es superior al millón de millones de dólares, lo que es equivalente a casi 10 veces el volumen diario de transacciones comerciales tanto de bienes como de servicios a nivel mundial", Botello, M. H., Finazas Estratégicas, Invertia, Centro Bursátil Monterrey, 21/09/00, p. 47.

(12) González, S. y J. Mascareñas, op. cit, p. 66. 